\title{
SEASONAL AND TIME-TREND VARIATION OF ALCOHOL-IMPAIRED DRIVERS AT PREVENTIVE SOBRIETY CHECKPOINTS
}

Helena Chuliáa ${ }^{a}$ Montserrat Guillén ${ }^{b, *}$ and Oscar Llatje

${ }^{a}$ Department of Econometrics and Riskcenter-IREA, University of Barcelona. Av. Diagonal, 690, 08034 Barcelona, Spain. Email: hchulia@ub.edu

${ }^{\mathrm{b}}$ Department of Econometrics and Riskcenter-IREA, University of Barcelona. Av. Diagonal, 690, 08034 Barcelona, Spain. Email: mguillen@ub.edu

Oscar LLatje ${ }^{\mathrm{c}}$

${ }^{\mathrm{c} C a t a l a n}$ Traffic Authority, Generalitat de Catalunya. Email: oscarll@gencat.cat

* Corresponding author Montserrat Guillén Department of Econometrics and RiskcenterIREA, University of Barcelona. Diagonal, 690, 08034 Barcelona, Spain. Email: mguillen@ub.edu, Tel: +34934037039 Fax: +34934021821. 


\begin{abstract}
Objective: We aim to analyse time evolution and seasonality of the outcomes of non-random alcohol concentration breath tests performed on drivers at sobriety checkpoints in Catalonia (Spain) from 2005 to 2012. Differences by gender are also explored.

Methods: Time series analyses of the monthly prevalence of drunk drivers by gender. The sample consisted of all drivers tested at non-random sobriety checkpoints in Catalonia (Spain) from 2005 to 2012 ( $n=3,985,000)$. Our outcome variable was the monthly prevalence of drivers with a breath alcohol concentration at or above the legal limit. The driver's gender was also registered.
\end{abstract}

Results: A decreasing trend in drunk-driving over time was found, the gender gap diminished after 2008 and disappeared in 2012. After adjusting for trend, the monthly coefficient presented the lowest value for males in January at $3.91 \%(\mathrm{p}<0.001)$ and the highest in July at $4.72 \%(\mathrm{p}<0.001)$ and September at $4.75 \%(\mathrm{p}<0.001)$. The monthly coefficient was lowest for females in January at $3.05 \%(\mathrm{p}<0.001)$ and highest in October at $4.12 \%(\mathrm{p}<0.001)$. After seasonal the lowest coefficient is found in winter both for men and women.

Conclusion: Seasonal patterns for male and female drivers testing positive at preventive nonrandom sobriety checkpoints indicate that the prevalence of drunk-driving peaks in spring for males and in autumn for females. We recommend that the authorities enforce campaigns that target male and female drinkers differently.

\title{
INTRODUCTION
}


Alcohol stands out as the most prevalent psychoactive substance both in those injured and those killed in traffic accidents (Isalberti et al., 2011). Preventive sobriety checkpoints trace the percentage of drunk drivers, but the authorities need to analyse these series along time and are worried that seasonal pattern may distort the process of identifying significant changes in the percent of drivers under the influence (DUI) of alcohol.

With more than 7.5 million inhabitants in 2012, the total number of vehicles in Catalonia (a Mediterranean region located in the northeast corner of Spain, whose capital and largest city is Barcelona) exceeds 5.0 million, while the number of drivers at the end of that year was over 4.1 million (Spanish Traffic Authority, 2012). In 2012 there were 336 traffic fatalities on Catalonia's roads, while 36,360 people were injured (1,980 severely) in a total of 23,368 road accidents with victims. Although the number of deaths had fallen by $48 \%$ since 2005 , toxicological analyses showed that an alarming 29\% of the fatalities in 2012 were associated with DUI (Catalan Traffic Authority, 2012). Hence the need for improved drink driving control strategies is imperative.

Given drunk driving's importance, the present paper addresses the following questions: first, are there seasonal variations and time trends in the percentage of alcohol-impaired drivers in Catalonia as detected at breath alcohol concentration (BrAC) controls? And, if so, is gender associated with the time-trend and seasonality patterns? To answer these questions, we used a database, provided by regional traffic authorities, that includes a total of $3,985,000$ nonrandom breath tests carried out between 2005 and 2012 on the main roads of Catalonia (Spain) by traffic police.

In most countries, traffic authorities collect information on drivers' breath alcohol concentration and conduct either non-random or random breath tests (RBT or non-RBT) at roadblocks at any time. Law enforcement officers are allowed to stop any driver on their own 
criterion, and to perform a BrAC test, whether or not the driver is showing any visible signs of impairment. Random selection allows extrapolating results to the general population of drivers and eliminates bias of intentional checkpoints, but it does not focus on hot spots. Nonrandom selection of drivers has a preventive effect, because the police officers locate sobriety controls near alcohol outlets such as restaurants or leisure areas where the risk of driving under the influence of alcohol is high, but they do not represent the whole population of drivers.

Non-RBT, usually performed at sobriety checkpoints, show that the percentage of alcoholimpaired drivers can be as high as 20\% (see, Campos et al., 2012, for a study in Brazil). However, legal limits may vary across the globe, so any cross-country comparisons should be conducted with caution. Gruenewald et al. (2010) examine the influence of on-premise alcohol-outlet densities and of drinking-driver densities on rates of alcohol-related motor vehicle crashes. Finally, drawing on data from the Behavioral Risk Factor Surveillance System, Bergen et al. (2012) show that the percentage of the US population reporting at least one alcohol-impaired driving episode over the preceding 30 days was $2.2 \%$ for 2006 and 2008 combined.

Although we will only analyse non-RBT in our study, we want to mention some recent examples of RBT results, including those reported by Li et al. (2013) who find that a higher BrAC increases the risk of death or serious injury in road accidents in Hong Kong, though they report no relationship between the risk of crashes involving slight injury and mean BrAC. Vanlaar (2005) conducts a national roadside survey in Belgium (comprising a BrAC test and a short questionnaire identifying individual variables) to estimate the proportion of drink drivers and to establish their profile. He finds that the percentage of drivers with a blood alcohol concentration (BAC) at or above the legal limit of $50 \mathrm{mg} / \mathrm{dl}$ was significantly higher on weekend nights than at all other times in the week. Finally, Alcañiz et al. (2014) 
report a case study in which the prevalence of alcohol-impaired driving is estimated for the general population of drivers in Catalonia in 2012. They estimate a prevalence of $1.29 \%$, which is roughly a third of the rate obtained in non-random tests.

In all the studies, on drunk driving, no seasonal analysis is carried out and thus, there is no evidence of a changing pattern along the year. On the contrary, gender and age differences in alcohol consumption have been analysed in various studies. Jones and Holmgren (2009), for example, studied the BAC results of those apprehended in Sweden for driving under the influence of alcohol (DUIA) over an 8-year period (2000-2007). They found that the vast majority of offenders were men $(89.5 \%)$. However, the mean BAC in the male sample did not differ significantly from that in the female sample. Likewise, using data collected from Long Beach and Fort Lauderdale, Peck et al. (2008) show differences between drivers by age (those under 21 and those aged 21 and older). Thus, BACs in drivers under 21 are associated with higher relative crash risks than predicted from the additive effect of $\mathrm{BAC}$ and age.

Seasonality as such has been routinely included in alcohol consumption studies, but not in connection to driving. For example, Clapp et al. (2008) examine seasonal, temporal and contextual variation in drinking among college students at a large West Coast university and find that seasonal trends in college student drinking mirror seasonal trends demonstrated in the general population. Demographic characteristics, such as race and ethnicity, are important determinants of seasonal variation in self-reports of recent alcohol consumption and should therefore be taken into account by researchers and policymakers (Carpenter, 2003). Lloyd et al. (2013) show that acute alcohol intoxication cases requiring ambulance, emergency department and hospital in-patient treatment in Australia increase substantially on days preceding public holidays and other major social events. Likewise, Del Río et al. (2002) report that the differences in alcohol intake over the seasons of the year among those that drink daily in Spain point to the need for alcohol consumption assessments to take seasonal 
variation into consideration. Finally, seasonal variation in alcohol consumption has also been found in many countries, for instance in Estonia by Silm and Ahas (2005), in Scotland by Uitenbroek (1996) and in the United States by Cho et al. (2001).

The aforementioned studies may be an indication that although gender differences and seasonality have been ignored in studies of impaired driving, they should be analysed.

\section{METHOD}

\section{Data}

We used data provided by the regional traffic authorities from a total of 3,985,000 non-RBTs carried out by traffic police between 2005 and 2012 on the main roads in Catalonia. We considered all non-RBT. Around 6\% of tests are performed for reasons other than prevention (including, post-accident, drivers showing signs of intoxication or following traffic violations), while the remaining $94 \%$ of all non-RBT carried out by traffic authorities are preventive alcohol tests. In order to satisfy preventive objectives, sobriety checkpoints were set up intentionally at strategic locations and during high-risk time-slots. Apart from that, drivers were selected on the basis of observable suspicious driving. These included, for instance, swerving, braking erratically or drifting. The traffic authorities confirm that the selection procedures did not change over time and that they do not differ by sex. Moreover, suspicion of drunk driving is actually previous to the decision to stop the vehicle, so the gender is revealed once the car is stopped.

Table 1 shows the sample size disaggregated by year and gender with the descriptive statistics of the observed monthly percentage of alcohol-impaired drivers. The number of male drivers is much larger that the number of female drivers in the region (see Alcañiz et al, 2014) and this is the reason why many more tests are undergone by men than by women.

[Insert Table 1 about here] 


\section{Variables}

Statutory blood-alcohol limits for driving differ between countries within Europe. In Spain, limits are expressed in terms of breath alcohol concentration (BrAC), measured in milligrams of alcohol per litre of breath. A BrAC is positive if it exceeds $0.25 \mathrm{mg} / \mathrm{l}$, and it may be prosecuted as criminal if it exceeds $0.60 \mathrm{mg} / \mathrm{l}$. The minimum level is set to $0.15 \mathrm{mg} / \mathrm{l}$ for inexpert and professional drivers.

BrAC values can be related to blood alcohol concentration (BAC) levels expressed in grams per litre of blood. Unfortunately, there is no universal proportionality constant between these two magnitudes (Jones, 2010). In Spain, the average blood/breath ratio of alcohol is 2:1. Hence, the standard administrative BAC limit is $50 \mathrm{mg} / \mathrm{dl}$ while the criminal limit is 120 $\mathrm{mg} / \mathrm{dl}$.

First, our outcome variable was the monthly prevalence of alcohol-impaired drivers, i.e., the percentage of tested drivers that have a BrAC test result at or above $0.25 \mathrm{mg} / \mathrm{l}$. The driver's gender was also registered. In a second step, monthly data were aggregated by seasons. The months were grouped into the following seasons based on the month in which the season was considered to begin: winter (December-February), spring (March-May), summer (JuneAugust), and autumn (September-November).

\section{Statistical analysis}

We assessed the extent and significance of gender differences and seasonal and time-trend variations in our alcohol-impaired driver data. A graphical analysis was performed and then regression analysis was used to decompose the data series into its components (i.e., the longterm time-trend, seasonal variation around that trend, and error). We estimated the regression model with both monthly and seasonal data. Thus, the total sample size for the period 2005 through 2012 was 96 months (32 seasons). 
Regression models for non-stationary series* give spurious results, which means that one may obtain apparently significant relationships from unrelated variables. Thus, we tested for the presence of a stochastic trend, in fact this is technically known as "a unit root" in statistics, for each of the series. We applied the Augmented Dickey-Fuller (1979) test (henceforth, the ADF test), which has the unit root process as the null hypothesis (the series is integrated of order one, i.e. non-stationary, against integrated of order zero, i.e. stationary). Dickey and Fuller (1979) use the following regression equation for a process with intercept and trend:

$$
\Delta \mathrm{Y}_{\mathrm{t}}=\alpha+\beta \mathrm{t}+\rho \mathrm{Y}_{\mathrm{t}-1}+\sum_{\mathrm{j}=1}^{\mathrm{p}} \gamma_{\mathrm{j}} \Delta \mathrm{Y}_{\mathrm{t}-1}+\varepsilon_{\mathrm{t}}
$$

The test for a unit root in the series is a test of the null hypothesis that $\rho=0$. If the hypothesis cannot be rejected the series is assumed to be non-stationary.

Perron (1989) argued that the presence of a structural break can change the properties of traditional unit root tests, affecting the conclusions of these tests. Thus, we also tested the stationarity of the series in the presence of structural breaks. To this end, we applied the Zivot and Andrews (1992) test. These authors proposed to introduce a dummy variable in the regression model formulated by Dickey and Fuller to detect the structural break. The null hypothesis in the Zivot and Andrews' (1992) test is a unit root process. The alternative hypothesis is a stationary process that allows for a one-time unknown break in intercept and/or slope. The position of the structural break is estimated recursively by choosing the point in time for which the absolute value of the Augmented Dickey Fuller test statistic is minimized. Zivot and Andrews (1992) use the following regression equation corresponding to the model with a one-time unknown break in slope:

\footnotetext{
* A weakly stationary process has a constant mean, a constant variance and a constant autocovariance structure.
} 


$$
\Delta \mathrm{Y}_{\mathrm{t}}=\alpha+\beta \mathrm{t}+\theta_{1} \mathrm{~T}_{\mathrm{t}}(\lambda)+\rho \mathrm{Y}_{\mathrm{t}-1}+\sum_{\mathrm{j}=1}^{\mathrm{p}} \gamma_{\mathrm{j}} \Delta \mathrm{Y}_{\mathrm{t}-1}+\varepsilon_{\mathrm{t}}
$$

where $T_{t}(\lambda)=t-\lambda$ for $t>\lambda$ and 0 otherwise.

Our results based on the ADF test show that the null hypothesis of a unit root is rejected both for males $(\mathrm{ADF}$ test $=-6.04)$ and females $(\mathrm{ADF}$ test $=-5.92)$. The critical values at $1 \%, 5 \%$ and 10\% significance level of Mackinnon (1991) for the ADF are $-4.05,-3.45$ and -3.15 , respectively. Likewise, our results based on the ZA test showed that the null hypothesis of a unit root is rejected for both series. The ZA test equals -7.23 for males and -8.02 for females. Critical values at $1 \%, 5 \%$ and $10 \%$ significance level are $-4.93,-4.42$ and -4.11 , respectively. The test identified the break points as September 2005 for the percentage of male alcoholimpaired drivers' series and March 2009 for the percentage of female alcohol-impaired drivers' series. Thus, given that our series are stationary, in our regression analysis we use both series in levels, i.e. with no other transformation.

To test for equality of means between the percentages of male and female alcohol-impaired drivers, we carried out an Analysis of Variance (ANOVA) test. Next, we decomposed the data series into its components (the long-term time-trend, monthly or seasonal variation depending on the model around that trend, and error) by means of time-series models. Given the patterns we observed, we included a linear time-trend in the model for males and a quadratic function in the model for females to approximate the trending patterns. We also included lags to remove autocorrelation in the series where necessary. To avoid multicollinearity when including our dummy variables for each month, we did not include an intercept in our regression model. Thus, we used the following regression equation for men:

$$
\begin{aligned}
& Y_{t}=\beta t+\gamma Y_{t-1}+\theta_{\text {Jan }} D_{\text {Jan }, \mathrm{t}}+\theta_{\text {Feb }} D_{\text {Feb }, \mathrm{t}}+\theta_{\text {Mar }} D_{\text {Mar }, \mathrm{t}}+\theta_{\text {Apr }} D_{\text {Apr }, \mathrm{t}}+\theta_{\text {May }} D_{\text {May }, \mathrm{t}}+\theta_{\text {Jun }} D_{\text {Jun }, \mathrm{t}}+ \\
& +\theta_{\text {Jul }} D_{\text {Jul }, \mathrm{t}}+\theta_{\text {Aug }} D_{\text {Aug }, \mathrm{t}}+\theta_{\text {Sep }} D_{\text {Sep }, \mathrm{t}}+\theta_{\text {Oct }} D_{\text {Oct }, \mathrm{t}}+\theta_{\text {Nov }} D_{\text {Nov }, \mathrm{t}}+\theta_{\text {Dec }} D_{\text {Dec }, \mathrm{t}}+\varepsilon_{\mathrm{t}}
\end{aligned}
$$


And for women:

$$
\begin{aligned}
& Y_{t}=\beta_{1} t+\beta_{2} t^{2}+\theta_{\text {Jan }} D_{\text {Jan }, \mathrm{t}}+\theta_{\text {Feb }} D_{\text {Feb }, \mathrm{t}}+\theta_{\text {Mar }} D_{\text {Mar }, \mathrm{t}}+\theta_{\text {Apr }} D_{\text {Apr }, \mathrm{t}}+\theta_{\text {May }} D_{\text {May }, \mathrm{t}}+\theta_{\text {Jun }} D_{\text {Jun }, \mathrm{t}}+ \\
& +\theta_{\text {Jul }} D_{\text {Jul }, \mathrm{t}}+\theta_{\text {Aug }} D_{\text {Aug }, \mathrm{t}}+\theta_{\text {Sep }} D_{\text {Sep }, \mathrm{t}}+\theta_{\text {Oct }} D_{\text {Oct }, \mathrm{t}}+\theta_{\text {Nov }} D_{\text {Nov }, \mathrm{t}}+\theta_{\text {Dec }} D_{\text {Dec }, \mathrm{t}}+\varepsilon_{\mathrm{t}}
\end{aligned}
$$

where $D_{\text {Jan, }}$ is a dummy variable that takes the value 1 in January and 0 otherwise. A similar definition applies to all other months.

Finally, to test for significant differences in the percentages of alcohol-impaired drivers between months, we used a Wald test from the point estimates and the standard errors of the parameters.

\section{RESULTS}

\section{Monthly analysis}

The observed series illustrate the nature and magnitude of time-trend and seasonal variations in males and females, so the evolution in the percentage of alcohol-impaired drivers across the sample period is plotted in Figure 1. During the period 2005-2008, the percentage of female alcohol-impaired drivers increased. Interestingly, between 2005 and 2008 the percentage of alcohol-impaired drivers is noticeably higher in males than in females; however, after this date, the respective percentages are closer and present a decreasing time trend, and they become very similar in 2012.

[Insert Figure 1 about here]

Table 2 (Panel A) displays the means of the percentage of male and female alcohol-impaired drivers each month during the entire sample period. For both males and females, January and December are the months with the lowest percentages of alcohol-impaired drivers. In both cases, July, August, September and October are months with a higher percentage of alcohol- 
impaired drivers to which April is added in the case of males and November in the case of females.

[Insert Table 2 about here]

The results of the ANOVA tests are reported in Table 3 and show that the percentage of male and female alcohol-impaired drivers differed significantly during the entire period. However, the ANOVA test does not reject the null hypothesis that the percentage of male and female alcohol-impaired drivers is equal in 2012, thus confirming the similar pattern presented by the two genders in 2012.

[Insert Table 3 about here]

Focusing on the period 2009-2012, Daniel's non-parametric test for trend indicates that the percentages of monthly male and female alcohol-impaired drivers present a significant trend (males: test $=5.20, \mathrm{p}=<0.001$; females: test $=4.03, \mathrm{p}=<0.001)^{\dagger}{ }^{\dagger}$ However, Kruskal-Wallis' nonparametric test for seasonality shows that the distribution of the percentages of male and female alcohol-impaired drivers do not differ significantly between months (males: $\chi_{11}^{2}=9.45, \mathrm{p}=0.580$; females: $\chi_{11}^{2}=12.77, \mathrm{p}=0.308$ ). However, this test does not control for a general time-trend.

The regression results for monthly data are shown in Table 4. After adjusting for trend and lags in the regression, we can measure the net influence of the month in which the observation is obtained. We found that the monthly coefficient in January presents the lowest value for males $3.91 \%(\mathrm{p}<0.001)$ while it is highest in July $4.72 \%(\mathrm{p}<0.001)$ and September $4.75 \%(\mathrm{p}<0.001)$. The monthly coefficient in January 3.05\% $(\mathrm{p}<0.001)$ is the lowest for females and it is highest in October 4.12\% $(\mathrm{p}<0.001)$. Wald test results show that the

\footnotetext{
† Spearman's rank correlation test is referred to as Daniel's test for trend when one of the paired observations is time or sequence number.
} 
percentage of male alcohol-impaired drivers is significantly lower in January when compared to April $\left(\chi_{1}^{2}=6.48, \mathrm{p}=0.011\right)$, July $\left(\chi_{1}^{2}=6.09, \mathrm{p}=0.013\right)$, August $\left(\chi_{1}^{2}=3.97, \mathrm{p}=0.046\right)$ and September $\left(\chi_{1}^{2}=7.22, \mathrm{p}=0.007\right)$, respectively and in December with respect to April $\left(\chi_{1}^{2}=4.22, \mathrm{p}=0.040\right)$, July $\left(\chi_{1}^{2}=4.64, \mathrm{p}=0.031\right)$ and September $\left(\chi_{1}^{2}=5.77, \mathrm{p}=0.016\right)$. In the case of female alcohol-impaired drivers, the percentage is lower in January when compared to May $\left(\chi_{1}^{2}=4.25, \mathrm{p}=0.039\right)$, July $\left(\chi_{1}^{2}=4.28, \mathrm{p}=0.038\right)$, August $\left(\chi_{1}^{2}=9.21, \mathrm{p}=0.002\right)$, September $\left(\chi_{1}^{2}=9.78, \mathrm{p}=0.002\right)$, October $\left(\chi_{1}^{2}=14.93, \mathrm{p}<0.001\right)$ and November $\left(\chi_{1}^{2}=14.44\right.$, $\mathrm{p}<0.001)$, respectively; in June when compared to August $\left(\chi_{1}^{2}=4.26, \mathrm{p}=0.039\right)$, September $\left(\chi_{1}^{2}=4.62, \mathrm{p}=0.031\right)$, October $\left(\chi_{1}^{2}=7.64, \mathrm{p}=0.006\right)$ and November $\left(\chi_{1}^{2}=4.48, \mathrm{p}=0.034\right)$, respectively and in December with respect to July $\left(\chi_{1}^{2}=3.91, \mathrm{p}=0.048\right)$, August $\left(\chi_{1}^{2}=8.87\right.$, $\mathrm{p}=0.003)$, September $\left(\chi_{1}^{2}=8.38, \mathrm{p}=0.003\right)$, October $\left(\chi_{1}^{2}=15.31, \mathrm{p}<0.001\right)$ and November $\left(\chi_{1}^{2}=13.65, \mathrm{p}<0.001\right)$, respectively. Results also show that the percentage of female alcoholimpaired drivers is significantly higher in October when compared to February $\left(\chi_{1}^{2}=5.92\right.$, $\mathrm{p}=0.015)$, April $\left(\chi_{1}^{2}=4.18, \mathrm{p}<0.041\right)$ and May $\left(\chi_{1}^{2}=4.26, \mathrm{p}<0.038\right)$, respectively The value of the adjusted $\mathrm{R}^{2}$ at $0.84(0.52)$ shows that over $84 \%(52 \%)$ of the variation in the percentage of male (female) alcohol-impaired drivers was predicted by our models. Regarding the proportion of variance explained, which is much lower for women than for men, we note that the monthly prevalence of drunk driving in men is higher than in women and it is more related to seasonal and weather patterns, whereas the prevalence in women suffer relatively high fluctuations which are difficult to explain.

[Insert Table 4 about here]

\section{Seasonal analysis}


Table 2 (Panel B) displays the means of the percentage of male and female alcohol-impaired drivers detected at non-RBT sobriety checkpoints during each season for the entire sample. These figures show a seasonal variation - thus, the fewest alcohol-impaired drivers are recorded in winter, while the number rises gradually in spring and summer to peak in autumn. However, in the case of male alcohol-impaired drivers the percentage figures are similar in summer and autumn. Interestingly, this seasonal distribution of male alcohol-impaired drivers changes in 2009-2012 subsample (see Table 2, Panel C), with spring and summer emerging as the seasons with the highest percentage.

The regression analysis corresponding to seasonally data is shown in Table 5. Results show that the seasonal coefficient, after controlling for trend, is $4.38 \%(\mathrm{p}=0.003)$ for males in spring and just $3.56 \%(\mathrm{p}=0.016)$ in winter. The seasonal coefficient is $1.80 \%(\mathrm{p}=0.002)$ for females in autumn and just $0.82 \%(\mathrm{p}=0.259)$ in winter. Wald tests reveal that the percentages of male and female alcohol-impaired drivers are significantly lower in winter than in the other seasons, i.e., spring $\left(\chi_{1}^{2}=9.19, \mathrm{p}=0.002\right.$ for males and $\chi_{1}^{2}=7.55, \mathrm{p}=0.006$ for females $)$, summer $\left(\chi_{1}^{2}=5.02, \mathrm{p}=0.025\right.$ for males and $\chi_{1}^{2}=7.65, \mathrm{p}=0.006$ for females $)$ and autumn $\left(\chi_{1}^{2}=11.38, \mathrm{p}<0.001\right.$ for males and $\chi_{1}^{2}=19.57, \mathrm{p}<0.001$ for females $)$. A linear trend and a quadratic function do not appear to be significantly different from zero in the female model. The value of the adjusted $\mathrm{R}^{2}$ shows that over $92 \%(60 \%)$ of the variation in the percentage of male (female) alcohol-impaired drivers was predicted by our models.

[Insert Table 5 about here]

\section{DISCUSSION}

Alcohol has long been known to produce dose-dependent effects on a range of cognitive abilities that are important to driving, and has consistently been identified as a major factor in 
crash risk and culpability (Kelly et al., 2004). Thus, any efforts to reduce the number of alcohol-impaired drivers are important. However, for these efforts to be effective it is necessary to understand the time-trend, seasonality variations and gender differences in the number of alcohol-impaired drivers. Our findings contribute further evidence to an increasing body of studies indicating that environmental factors have an impact on the risk for alcohol misuse and, consequently, on traffic accidents.

After adjusting for trend, we have found that the drunk-driving prevalence rate at non-RBT locations is the lowest in winter for both men and women. It peaks in the summer for males and in autumn for females. These results hold for both monthly and seasonal data, but only for the population of drivers for which this sample is representative. This is indeed the group of drivers that were either involved in accidents or traffic violations, showed signs of intoxication by abnormal driving or were driving near sobriety checkpoints, which are usually located at high-risk places. It would be incorrect to generalize these results to the whole population of drivers. However, since traffic officers do not select drivers on the basis of gender, we argue that the gender differences that we find are valid for the population under study.

We conclude that female drivers exceeding BrAC legal limits at non-RBT controls exhibit a seasonal pattern that differs from that presented by their male counterparts. This behaviour may be explained by alcohol excess in men being associated to outdoor activities which usually take place in spring and summer, while in women they could be associated to psychological factors that increase in autumn. As noted by authors studying these phenomena, the incidence of depression and anxiety in women is larger than in men in Autumn (Simkin et al., 2003), and there is peak of violent and suicidal acts in psychiatric patients in the fall until November (Paalova and Tiihonen, 2010) and diminishes in spring for women (Mergl et al. 2010). We note that the lags in the monthly and seasonal models cannot 
be compared directly because they are estimated with different data, i.e. monthly or aggregated, accordingly.

In an earlier analysis, we excluded from the sample the $6 \%$ tested drivers who showed signs of intoxication, had a crash or committed a traffic violation. Although there are some differences in the results compared with the current analysis, the main conclusions remain. We there found that the season when men peak was summer, but we explain this fact by the exclusion of the controls which took place in Eastern Holiday, when the number of trips increases significantly during that holiday period and a number of non-RBT are performed to either drivers with accidents, traffic violations and showing symptoms.

We reject the null hypothesis that a gender difference can be found in the prevalence detected in the last year of the sample period, which suggests that the drink-driving behaviour of the genders converges. Despite this, on the basis of the earlier detection of different seasonality drinking patterns between the genders, we recommend that the authorities take into consideration that the male drunk drivers that are represented by non-RBT experiment a peak in the summer while this also happens in autumn for female drunk drivers. We suggest that preventive actions and campaigns should take these seasonal differences into consideration. But, for the success of and advertising campaign, it is necessary to link publicity to enforcement (Cameron et al., 1993 and Macpherson \& Lewis, 1998). Since strong penalties exist in traffic legislation, we believe that advertising campaigns can benefit from the knowledge about specific months during the year when alcohol misuse is more prevalent. We encourage research regarding gender differences in response to traffic safety messages as well as evidence on the effectiveness of media campaigns in reducing DUI.

\section{ACKNOWLEDGEMENTS}


We wish to thank researchers at the UB Riskcenter, above all Lluís Ramon, Miguel Santolino and Manuela Alcañiz for helpful discussions. Finally, we gratefully acknowledge the Catalan Traffic Authority for conducting the field work and providing the data.

This work was supported by Spanish Ministry of Economy Grant Nos. ECO2013-48326-C21-P and ECO2015-66314-R and ICREA Academia. 


\section{REFERENCES}

Alcañiz M., Guillén M., Santolino M., Sánchez-Moscona D., Llatje O., \& Ramon Ll. (2014). Prevalence of alcohol-impaired drivers based on random breath tests in a roadside survey in Catalonia (Spain). Accident Analysis and Prevention, 65, 131-141.

Bergen G., Shults R. A., Beck L. F., \& Qayad, M. (2012). Self-reported alcohol-impaired driving in the U.S., 2006 and 2008. American Journal of Preventive Medicine, 42, 142-149.

Cameron M. H., Haworth N., Oxley J., Newstead S., \& Le T. (1993). Evaluation of Transport Accident Commission road safety television advertising. Report No.52, Monash University Accident Research Centre.

Campos V. R., Salgado R., Rocha M. C., Duailibi S., \& Laranjeira R. (2012). Drinking and driving: Characteristics of drivers with positive breathalyzer. Revista de Psiquiatría Clínica, 39, 166-171.

Carpenter C. (2003). Seasonal variation in self-reports of recent alcohol consumption: racial and ethnic differences. Journal of Studies on Alcohol, 64, 415-418.

Catalan Traffic Authority. (2012). 2012 statistical report on traffic accidents. http://transit.gencat.cat/web/.content/documents/seguretat_viaria/anuari_2012.pdf

Cho, Y. I., Johnson, T. P., \& Fendrich, M. (2001). Monthly variations in self-reports of alcohol consumption. Journal of Studies on Alcohol, 62, 268-272.

Clapp J. D., Johnson M. B., Shillington A.M., Lange J. E., \& Voas R. B. (2008). Breath alcohol concentrations of college students in field settings: seasonal, temporal, and contextual patterns. Journal of Studies on Alcohol and Drugs, 69, 323-331.

Del Río M. C., Prada C., \& Alvarez F. J. (2002). Drinking habits throughout the seasons of the year in the Spanish population. Journal of Studies on Alcohol, 63, 577-580. 
Dickey D. A., \& Fuller W. A. (1979). Distribution of the estimators for autoregressive time series with a unit root. Journal of the American Statistical Association, 74, 427-431.

Gruenewald P. J, Johnson F. W. (2010). Drinking, driving, and crashing: a traffic-flow model of alcohol-related motor vehicle accidents. Journal of Studies on Alcohol and Drugs, 71, 237 248.

Isalberti, C., Van Der Linden, T., Legrand, S., Verstraete, A., Bernhoft, I. M., Hels, T., Olesen, M. N., Houwing, S., Houtenbos, M., \& Mathijssen, R. (2011). Prevalence of alcohol and other psychoactive substances in injured and killed drivers. DRUID 2011. https://biblio.ugent.be/publication/1166367.

Jones A. W., \& Holmgren A. (2009). Age and gender differences in blood-alcohol concentration in apprehended drivers in relation to the amounts of alcohol consumed. Forensic Science International, 188, 40-45.

Jones A. W. (2010). The relationship between blood alcohol concentration (BAC) and breath alcohol concentration (BrAC): A review of the evidence. Road Safety Web Publication, 15. Department for Transport, London.

Kelly E., Darke S., \& Ross J. (2004). A review of drug use and driving: epidemiology, impairment, risk factors and risk perceptions. Drug and Alcohol Review, 23, 319-344.

Li Y. C., Sze N. N., Wong S. C., Tsui K. L., \& So F. L. (2013). Effects of drink driving on crash risk based on random breath test data. Hong Kong Journal of Emergency Medicine, 20, 146-154.

Lloyd B., Matthews S., Livingston M., Jayasekara H., \& Smith K. (2013). Alcohol intoxication in the context of major public holidays, sporting and social events: a time-series analysis in Melbourne, Australia, 2000-2009. Addiction, 108, 701-709. 
MacKinnon J. G. (1991). Critical values for cointegration tests. In Engle R. F. \& Granger C. W. J. (Eds.), Long-run economic relationships: Readings in cointegration (pp. 267-276). Oxford: Oxford University Press.

Macpherson T., \& Lewis T. (1998). New Zealand drink-driving statistics: The effectiveness of road safety television advertising. Marketing Bulletin, 9, 40-51.

Mergl R., Havers I., Althaus D., Rihmer Z., Schmidtke A., Lehfeld H., Niklewski G., \& Hegerl U. (2010). Seasonality of suicide attempts: association with gender. European Archives of Psychiatry and Clinical Neuroscience, 260, 393-400.

Paavola, P., \& Tiihonen, J. (2010). Seasonal variation of seclusion incidents from violent and suicidal acts in forensic psychiatric patients. International journal of law and psychiatry, 33, 27-34.

Peck R. C, Gebers M. A, Voas R. B., \& Romano E. (2008). The relationship between blood alcohol concentration (BAC), age, and crash risk. Journal of Safety Research, 39, 311-319.

Perron P. (1989). The Great Crash, the oil price shock, and the unit root hypothesis. Econometrica, 57, 1361-1401.

Silm S., \& Ahas R. (2005). Seasonality of alcohol-related phenomena in Estonia. International Journal of Biometeorology, 49, 215-223.

Simkin, S., Hawton, K., Yip, P. S., \& Yam, C. H. (2003). Seasonality in suicide: A study of farming suicides in England and Wales. Crisis: The Journal of Crisis Intervention and Suicide Prevention, 24, 93-97.

Spanish Traffic Authority. (2012). 2012 statistical information by region. http://www.dgt.es/Galerias/seguridad-vial/estadisticas-e-indicadores/parque-vehiculos/provy-tipos-vehiculos/V.4-y-V.4.C.A_parque-x-prov.-y-CC.AA-2012.xls 
Uitenbroek D. G. (1996). Seasonal variation in alcohol use. Journal of Studies on Alcohol, $57,47-52$.

Vanlaar W. (2005). Drink driving in Belgium: results from the third and improved roadside survey. Accident Analysis and Prevention, 37, 391-397.

Zivot E., \& Andrews D. W. K. (1992). Further evidence on the great crash, the oil-price shock, and the unit-root hypothesis. Journal of Business and Economic Statistics, 10, 251270. 


\section{TABLES}

Table 1. Sample size and descriptive statistics of non-random breath tests in Catalonia, Spain (2005-2012)

\begin{tabular}{lcc}
\hline & Males & Females \\
\hline N (number of BrAC tests) & \\
\hline Total & $3,300,368$ & 684,632 \\
2005 & 365,288 & 72,516 \\
2007 & 359,027 & 73,887 \\
2008 & 387,264 & 74,948 \\
2009 & 425,497 & 84,051 \\
2010 & 510,391 & 107,504 \\
2011 & 441,885 & 95,435 \\
2012 & 417,392 & 90,178 \\
\hline Monthly prevalence of drunk-driving & 393,624 & 86,113 \\
among tested drivers & & \\
\hline Mean & & \\
Standard deviation & $6.34 \%$ & $4.55 \%$ \\
Minimum & $1.30 \%$ & $0.71 \%$ \\
Maximum & $3.16 \%$ & $2.92 \%$ \\
\hline
\end{tabular}

Source: Data were provided by the regional traffic authorities. Prevalence measures the monthly percentage of controls in which BrACs exceeded $0.25 \mathrm{mg} / 1$. 
Table 2. Distribution of alcohol-impaired drivers (\%) in non-random breath tests by gender in Catalonia, Spain. Panel (A): Monthly distribution (2005-2012), Panel (B): Seasonal distribution (2005-2012), Panel (C): Seasonal distribution (2009-2012)

Males

Females

Panel (A). Monthly distribution (2005-2012)

\begin{tabular}{|c|c|c|}
\hline January & $\begin{array}{c}5.73 \\
(1.48)\end{array}$ & $\begin{array}{l}3.96 \\
(0.74)\end{array}$ \\
\hline February & $\begin{array}{c}6.14 \\
(1.53)\end{array}$ & $\begin{array}{c}4.43 \\
(0.68)\end{array}$ \\
\hline March & $\begin{array}{c}6.26 \\
(1.31)\end{array}$ & $\begin{array}{l}4.51 \\
(0.88)\end{array}$ \\
\hline April & $\begin{array}{c}6.58 \\
(1.35)\end{array}$ & $\begin{array}{l}4.51 \\
(0.59)\end{array}$ \\
\hline May & $\begin{array}{c}6.50 \\
(1.26)\end{array}$ & $\begin{array}{c}4.54 \\
(0.68)\end{array}$ \\
\hline June & $\begin{array}{c}6.28 \\
(1.38)\end{array}$ & $\begin{array}{l}4.35 \\
(0.58)\end{array}$ \\
\hline July & $\begin{array}{c}6.61 \\
(1.02)\end{array}$ & $\begin{array}{l}4.62 \\
(0.70)\end{array}$ \\
\hline August & $\begin{array}{c}6.55 \\
(0.98)\end{array}$ & $\begin{array}{l}4.80 \\
(0.73)\end{array}$ \\
\hline September & $\begin{array}{c}6.72 \\
(1.12)\end{array}$ & $\begin{array}{l}4.91 \\
(0.47)\end{array}$ \\
\hline October & $\begin{array}{c}6.52 \\
(1.36)\end{array}$ & $\begin{array}{l}5.05 \\
(0.57)\end{array}$ \\
\hline November & $\begin{array}{c}6.30 \\
(1.49)\end{array}$ & $\begin{array}{l}4.88 \\
(0.64)\end{array}$ \\
\hline December & $\begin{array}{c}5.84 \\
(1.69) \\
\end{array}$ & $\begin{array}{r}4.01 \\
(0.65) \\
\end{array}$ \\
\hline Panel (B). S & 012) & \\
\hline Winter & $\begin{array}{c}5.99 \\
(1.45)\end{array}$ & $\begin{array}{l}4.14 \\
(0.56)\end{array}$ \\
\hline Spring & $\begin{array}{c}6.44 \\
(1.26)\end{array}$ & $\begin{array}{l}4.52 \\
(0.60)\end{array}$ \\
\hline Summer & $\begin{array}{c}6.48 \\
(1.08)\end{array}$ & $\begin{array}{l}4.59 \\
(0.56)\end{array}$ \\
\hline Autumn & $\begin{array}{c}6.51 \\
(1.26) \\
\end{array}$ & $\begin{array}{r}4.95 \\
(0.39) \\
\end{array}$ \\
\hline Panel (C). S & 012) & \\
\hline Winter & $\begin{array}{c}5.01 \\
(1.11)\end{array}$ & $\begin{array}{l}4.15 \\
(0.72)\end{array}$ \\
\hline Spring & $\begin{array}{l}5.50 \\
(0.93)\end{array}$ & $\begin{array}{l}4.72 \\
(0.62)\end{array}$ \\
\hline Summer & $\begin{array}{c}5.58 \\
(0.76)\end{array}$ & $\begin{array}{l}4.62 \\
(0.49)\end{array}$ \\
\hline Autumn & $\begin{array}{c}5.46 \\
(0.63)\end{array}$ & $\begin{array}{c}4.92 \\
(0.30) \\
\end{array}$ \\
\hline
\end{tabular}

Note: Standard deviation in parentheses. Data were provided by the regional traffic authorities. Prevalence measures the percentage of stops in which BrACs exceeded $0.25 \mathrm{mg} / \mathrm{l}$. 
Table 3. Analysis of variance (ANOVA test) of mean equality between genders for the monthly prevalence of drunk-driving in non-random breath tests

in Catalonia, Spain (2005-2012)

\begin{tabular}{lcccc}
\hline & \multicolumn{2}{c}{ Entire sample } & \multicolumn{2}{c}{$\mathbf{2 0 1 2}$} \\
\hline & Mean & Anova test & Mean & Anova test \\
\hline Males & 6.34 & 139.58 & 4.32 & 0.68 \\
Females & 4.55 & $(<0.001)$ & 4.12 & $(0.419)$ \\
\hline
\end{tabular}

Note: This table shows the ANOVA test for the entire sample and 2012. The null hypothesis is that the percentage of male and female alcohol-impaired drivers is equal. p-values in parentheses. Data were provided by the regional traffic authorities. Prevalence measures the percentage of stops in which BrACs exceeded 0.25 $\mathrm{mg} / \mathrm{l}$. 
Table 4. Linear regression model results for the percent of alcohol-impaired drivers found at non-random breath tests in Catalonia, Spain (2005-2012), monthly data

\begin{tabular}{|c|c|c|c|c|c|c|}
\hline \multirow[b]{3}{*}{ Trend } & \multicolumn{3}{|c|}{ Males } & \multicolumn{3}{|c|}{ Females } \\
\hline & \multirow{2}{*}{$\begin{array}{c}\text { Coeff. } \\
-0.02 \\
(<0.001)\end{array}$} & \multicolumn{2}{|c|}{$95 \% \mathrm{CI}$} & \multirow{2}{*}{$\begin{array}{c}\text { Coeff. } \\
0.05 \\
(<0.001)\end{array}$} & \multicolumn{2}{|c|}{$95 \% \mathrm{CI}$} \\
\hline & & -0.04 & -0.01 & & 0.04 & 0.07 \\
\hline Trend $^{2}$ & - & & & $\begin{array}{c}-5.67 \times 10^{-4} \\
(<0.001)\end{array}$ & $-7.32 \times 10^{-4}$ & $-4.02 \times 10^{-4}$ \\
\hline $\operatorname{Lag}(-1)$ & $\begin{array}{c}0.47 \\
(<0.001)\end{array}$ & 0.23 & 0.72 & - & & \\
\hline \multicolumn{7}{|c|}{ Monthly variation } \\
\hline Jan & $\begin{array}{c}3.91 \\
(<0.001)\end{array}$ & 1.78 & 6.04 & $\begin{array}{c}3.05 \\
(<0.001)\end{array}$ & 2.61 & 3.48 \\
\hline Feb & $\begin{array}{c}4.40 \\
(<0.001)\end{array}$ & 2.29 & 6.51 & $\begin{array}{c}3.51 \\
(<0.001)\end{array}$ & 3.13 & 3.90 \\
\hline Mar & $\begin{array}{c}4.34 \\
(<0.001)\end{array}$ & 1.98 & 6.71 & $\begin{array}{c}3.59 \\
(<0.001)\end{array}$ & 3.12 & 4.06 \\
\hline Apr & $\begin{array}{c}4.63 \\
(<0.001)\end{array}$ & 2.44 & 6.83 & $\begin{array}{c}3.59 \\
(<0.001)\end{array}$ & 3.13 & 4.05 \\
\hline May & $\begin{array}{c}4.42 \\
(<0.001)\end{array}$ & 2.03 & 6.81 & $\begin{array}{c}3.62 \\
(<0.001)\end{array}$ & 3.24 & 4.00 \\
\hline Jun & $\begin{array}{c}4.27 \\
(<0.001)\end{array}$ & 2.06 & 6.48 & $\begin{array}{c}3.43 \\
(<0.001)\end{array}$ & 3.00 & 3.86 \\
\hline Jul & $\begin{array}{c}4.72 \\
(<0.001)\end{array}$ & 2.42 & 7.03 & $\begin{array}{c}3.69 \\
(<0.001)\end{array}$ & 3.12 & 4.26 \\
\hline Aug & $\begin{array}{c}4.52 \\
(<0.001)\end{array}$ & 2.19 & 6.85 & $\begin{array}{c}3.88 \\
(<0.001)\end{array}$ & 3.44 & 4.32 \\
\hline Sep & $\begin{array}{c}4.75 \\
(<0.001)\end{array}$ & 2.50 & 7.00 & $\begin{array}{c}3.99 \\
(<0.001)\end{array}$ & 3.44 & 4.54 \\
\hline Oct & $\begin{array}{c}4.49 \\
(<0.001)\end{array}$ & 2.14 & 6.84 & $\begin{array}{c}4.12 \\
(<0.001)\end{array}$ & 3.59 & 4.66 \\
\hline Nov & $\begin{array}{c}4.38 \\
(<0.001)\end{array}$ & 2.06 & 6.71 & $\begin{array}{c}3.97 \\
(<0.001)\end{array}$ & 3.53 & 4.40 \\
\hline Dec & $\begin{array}{c}4.06 \\
(<0.001)\end{array}$ & 1.75 & 6.36 & $\begin{array}{c}3.10 \\
(<0.001)\end{array}$ & 2.55 & 3.65 \\
\hline Adjusted $\mathrm{R}^{2}$ & 0.84 & & & 0.52 & & \\
\hline
\end{tabular}

Note: Models estimated using OLS and including lags to remove autocorrelation where necessary. Newey-West standard errors were estimated based on the assumption that the error structure may be heteroskedastic. p-values in parentheses. CI refers to confidence intervals. The number of months is equal to 96 . Data were provided by the regional traffic authorities. Prevalence measures the percentage of stops in which BrACs exceeded 0.25 $\mathrm{mg} / \mathrm{l}$. 
Table 5. Linear regression model results for the percent of alcohol-impaired drivers found at non-random breath tests in Catalonia, Spain (2005-2012), seasonally aggregated data

\begin{tabular}{|c|c|c|c|c|c|c|}
\hline \multirow{3}{*}{$\begin{array}{l}\text { Trend } \\
\text {. }\end{array}$} & \multicolumn{3}{|c|}{ Males } & \multicolumn{3}{|c|}{ Females } \\
\hline & \multirow{2}{*}{$\begin{array}{c}\text { Coeff. } \\
-0.07 \\
(0.003)\end{array}$} & \multicolumn{2}{|c|}{$95 \% \mathrm{CI}$} & \multirow{2}{*}{$\begin{array}{c}\text { Coeff. } \\
-\end{array}$} & \multicolumn{2}{|c|}{$95 \% \mathrm{CI}$} \\
\hline & & -0.11 & -0.03 & & & \\
\hline $\operatorname{Lag}(-1)$ & $\begin{array}{c}0.52 \\
(0.002)\end{array}$ & 0.23 & 0.82 & $\begin{array}{c}0.69 \\
(<0.001)\end{array}$ & 0.44 & 0.93 \\
\hline \multicolumn{7}{|c|}{ Seasonal Variation } \\
\hline Winter & $\begin{array}{c}3.56 \\
(0.016)\end{array}$ & 0.86 & 6.26 & $\begin{array}{c}0.82 \\
(0.259)\end{array}$ & -0.57 & 2.21 \\
\hline Spring & $\begin{array}{c}4.38 \\
(0.003)\end{array}$ & 1.81 & 6.94 & $\begin{array}{c}1.68 \\
(0.002)\end{array}$ & 0.72 & 2.64 \\
\hline Summer & $\begin{array}{c}4.24 \\
(0.003)\end{array}$ & 1.70 & 6.79 & $\begin{array}{c}1.49 \\
(0.018)\end{array}$ & 0.33 & 2.64 \\
\hline Autumn & $\begin{array}{c}4.32 \\
(0.003)\end{array}$ & 1.72 & 6.93 & $\begin{array}{c}1.80 \\
(0.002)\end{array}$ & 0.75 & 2.84 \\
\hline Adjusted $\mathrm{R}^{2}$ & 0.92 & & & 0.60 & & \\
\hline
\end{tabular}

Note: Models estimated using OLS and including lags to remove autocorrelation where necessary. The model for females does not include trend. Newey-West standard errors were estimated based on the assumption that the error structure may be heteroskedastic. p-values in parentheses. CI refers to confidence intervals. The number of seasons is equal to 32. Data were provided by the regional traffic authorities. Prevalence measures the percentage of stops in which BrACs exceeded $0.25 \mathrm{mg} / \mathrm{l}$. 


\section{FIGURES}

Figure 1. Percentage of alcohol-impaired drivers based on non-random breath tests in Catalonia, Spain (2005-2012)

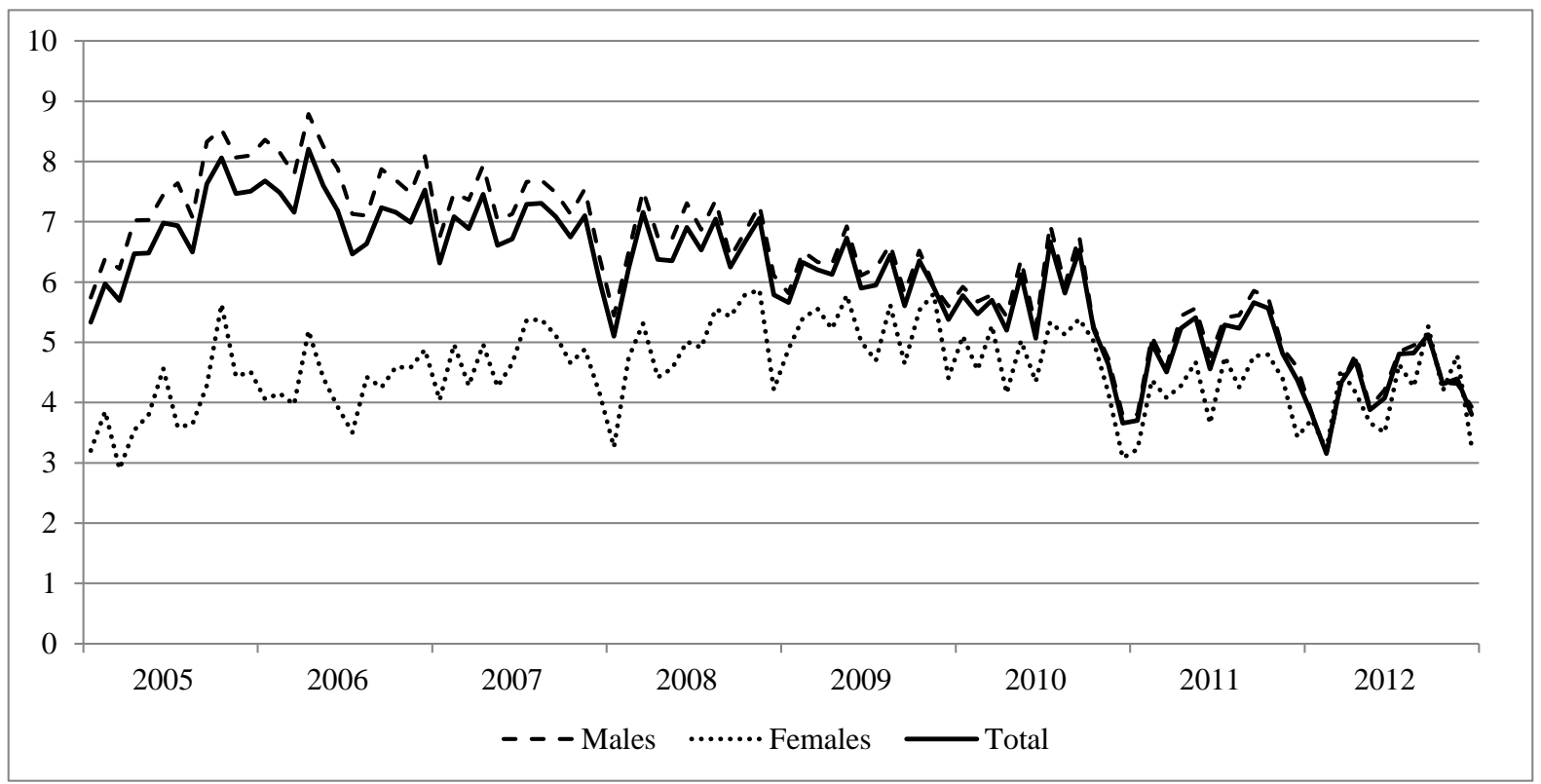

Source: Own elaboration with data provided by the regional traffic authorities 